\title{
The effects of indomethacin on refractoriness following exercise both with and without a bronchoconstrictor response
}

\author{
B.A. Wilson*, O. Bar-Or**, P.M. O'Byrne+
}

The effects of indomethacin on refractoriness following exercise both with and without a bronchoconstrictor response. B.A. Wilson, O. Bar-Or, P.M. O'Byrne. CERS Journals Ltd 1994.

ABSTRACT: Repeated exercise tests demonstrate refractoriness to the development of exercise-induced asthma (EIA). It is unclear whether it is the initial exercise per se or the resulting bronchoconstriction that causes the attenuated response to the second exercise challenge. This study was designed to determine whether the reported blocking of the refractory period by indomethacin requires a significant bronchoconstriction following the primary exercise challenge.

Thirteen asthmatic teenagers (aged 12-16 yrs) were tested on four visits. Each visit included two 7 min treadmill exercise challenges at $80 \%$ maximum heart rate, separated by a $30 \mathrm{~min}$ rest. Conditions for the second exercise challenge (Ch2) were always thermoneutral $\left(20-22^{\circ} \mathrm{C}\right.$ and $25-35 \%$ relative humidity ( $\left.\mathrm{RH}\right)$; whilst challenge one (Ch1) was completed twice in thermoneutral and twice in warm-humid breathing conditions $\left(33-35^{\circ} \mathrm{C}\right.$ and $\left.90-95 \% \mathrm{RH}\right)$. A pretreatment for 3 days in a double-blind design with either placebo or indomethacin was completed. Forced expiratory volume in one second $\left(\mathrm{FEV}_{1}\right)$ was measured before and repeatedly following each challenge. The \% fall in $\mathrm{FEV}_{1}$ following $\mathrm{Ch1}$ of the placebo thermoneutral trial was taken as reference. "Percent protection" at each visit was expressed as the decrease in EIA following Ch2, compared to reference.

Warm-humid breathing reduced the EIA post Ch1 by $75 \%$, whilst providing similar protection to thermoneutral conditions. Indomethacin had no significant effect on EIA after Ch1, but reduced "percent protection" for both warm-humid (from 67 to $16 \%$ ) and thermoneutral (from 70 to $26 \%$ ) conditions.

The data indicate that inhibitory prostaglandins play a major role in EIA refractoriness and suggest that the release of these prostaglandins is initiated by some exercise factor, independent of the development of bronchoconstriction.

Eur Respir J., 1994, 7, 2174-2178.
*School of Human Biology, University of Guelph, Guelph, Ontario, Canada. **Children's Exercise and Nutrition Centre, Department of Pediatrics, and ${ }^{+}$Cardiorespiratory Unit, Dept of Medicine, McMaster University, Hamilton, Ontario, Canada.

Correspondence: B.A. Wilson

School of Human Biology

University of Guelph

Guelph

Ontario N1G 2W1

Canada

Keywords: Exercise-induced asthma exercise-induced bronchoconstriction refractoriness

prostaglandins

Received: February 71993

Accepted after revision July 141994

Supported by the Ontario Thoracic Society
If an asthmatic subject repeats an exercise challenge within $90 \mathrm{~min}$, the resulting exercise-induced asthma (EIA) will often be considerably less severe than that following the first exercise challenge. The patient is then said to be refractory, and the time interval within which this phenomenon occurs is known as the "refractory period" [1].

Although refractoriness has traditionally been considered to result from the depletion of bronchoactive substances from lung mast cells, no reduction in release of neutrophil chemotactic factor (NCF) and histamine occurs with repeated exercise [2,3]. There have been conflicting reports concerning the role of airway temperature in refractoriness. GILBERT et al. [4], measuring temperatures of the tracheobronchial tree, found a reduced airway cooling after a second exercise when compared to that after the initial exercise in subjects showing minimal refractoriness. However, in an earlier study, with temperature measurements at the mouth, no reduction in heat or water loss was observed for repeated exercise [5]. Recently, the inhibitory prostaglandin $\mathrm{E}_{2}\left(\mathrm{PGE}_{2}\right)$ has been implicated in the cause of refractoriness [6-9]. As shown by O'BYRNE and JONES [9], pretreatment with indomethacin, a prostaglandin synthetase inhibitor, will prevent refractoriness to exercise.

It is not known, however, whether it is the initial exercise per se or the resulting bronchoconstriction that triggers the release of prostaglandins and causes refractoriness. The purpose of this study was to see whether the effect of indomethacin, a prostaglandin synthetase inhibitor could help answer this question. The inhalation of warm-humid air during the initial exercise has been shown to reduce, or even abolish, exercise-induced asthma (EIA) $[10,11]$, without abolishing refractoriness [12, 13]. This phenomenon provides a condition where the effects of prior exercise on refractoriness can be studied independent of the effects of prior EIA. This approach has been taken in the present study. 


\section{Methods}

\section{Subjects}

Thirteen asthmatic teenagers, aged 12-16 yrs (8 males and 5 females), were recruited for the study. A consent form was signed by the parent or guardian of each subject. All subjects had a history of EIA. None required medication during the time of the study, apart from occasional use of salbutamol to relieve symptoms. Salbutamol use was discontinued for at least $6 \mathrm{~h}$ prior to testing. The physical characteristics of the subjects and their spirometry at rest are summarized in table 1 . Only one of the subjects was obese and no other physical disorders were noted.

Apart from subject No. 1, they were all physically active, although they did not participate in competitive sports.

\section{Design and protocol}

Following an orientation/habituation session, subjects attended four experimental sessions, which were performed in random order, each including two $7 \mathrm{~min}$ treadmill exercise challenges ( $\mathrm{Ch} 1$ and $\mathrm{Ch} 2$, respectively) with a $30 \mathrm{~min}$ rest in between. These sessions differed in the treatment that the subject was given for 3 days before each visit (indomethacin or placebo), and in the conditions of inhaled air (thermoneutral or warm-humid) during Ch1. The sessions are summarized in table 2. All experimental sessions, for any given subject, were conducted at the same time of day and were separated by 4-7 days. Environmental conditions in the laboratory were constant at $20-22^{\circ} \mathrm{C}$, $25-35 \%$ relative humidity. Both subjects and investigators were blinded to the nature of pretreatment.

Table 1. - Subject's age, anthropometric characteristics and resting pulmonary functions at the beginning of the placebo-thermoneutral session

\begin{tabular}{lccccc}
\hline $\begin{array}{l}\text { Subject } \\
\text { No. }\end{array}$ & Sex & $\begin{array}{c}\text { Age } \\
\text { yrs }\end{array}$ & $\begin{array}{c}\text { Height } \\
\text { cm }\end{array}$ & $\begin{array}{c}\text { Weight } \\
\text { kg }\end{array}$ & $\begin{array}{c}\mathrm{FEV}_{1} \\
\% \text { pred }\end{array}$ \\
\hline 1 & F & 14 & 160 & 97 & 75 \\
2 & $\mathrm{~F}$ & 15 & 172 & 64 & 70 \\
3 & $\mathrm{M}$ & 12 & 155 & 44 & 72 \\
4 & $\mathrm{~F}$ & 13 & 172 & 62 & 119 \\
5 & $\mathrm{M}$ & 14 & 160 & 52 & 112 \\
6 & $\mathrm{M}$ & 15 & 171 & 49 & 89 \\
7 & $\mathrm{M}$ & 16 & 168 & 65 & 92 \\
8 & $\mathrm{M}$ & 12 & 159 & 65 & 63 \\
9 & $\mathrm{M}$ & 14 & 163 & 51 & 86 \\
10 & $\mathrm{M}$ & 15 & 152 & 50 & 85 \\
11 & $\mathrm{M}$ & 12 & 150 & 49 & 77 \\
12 & $\mathrm{~F}$ & 13 & 170 & 62 & 84 \\
13 & $\mathrm{~F}$ & 15 & 152 & 44 & 91 \\
\hline
\end{tabular}

$\mathrm{M}$ : male; $\mathrm{F}$ : female; $\mathrm{FEV}_{1}$ : forced expiratory volume in one second.
Table 2. - Three day pretreatment and characteristics of the inspired air during the two exercise challenges, by session

\begin{tabular}{llll}
\hline Session & Pretreatment & \multicolumn{2}{c}{ Inspired air } \\
& & Ch1 & Ch2 \\
\hline A & Placebo & Neutral & Neutral \\
B & Placebo & Warm-humid & Neutral \\
C & Indomethacin & Neutral & Neutral \\
D & Indomethacin & Warm-humid & Neutral \\
\hline
\end{tabular}

Neutral $=20-22^{\circ} \mathrm{C}, 25-35 \%$ relative humidity. Warm-humid $=33-35^{\circ} \mathrm{C}, 90-95 \%$ relative humidity. Ch1: Challenge $1 ; \mathrm{Ch} 2$ : Challenge 2.

The orientation/habituation session included physical examination, interview regarding the child's habitual physical activity, and practice in using the spirometer, the breathing system and the treadmill. In addition, the walking/running speed and slope that caused the heart rate (HR) to increase to $160-175$ beats $\cdot \mathrm{min}^{-1}$ were established for each child and utilized in all subsequent sessions.

Twice a day, during the 3 days before each experimental session, subjects took an orange-flavoured syrup that contained indomethacin $\left(0.75 \mathrm{mg} \cdot \mathrm{kg}^{-1}\right.$ body weight daily) or placebo. Thus, it was impossible for them to identify the active medication. In each experimental session, resting spirometry was measured in triplicate, using a calibrated wedge spirometer (Vitalograph). These included: forced vital capacity (FVC) and forced expiratory volume in one second $\left(\mathrm{FEV}_{1}\right)$. The subject was then fitted with a heart rate monitor (Polar Sport Tester PE-2500, Bionetics, Toronto, Ontario, Canada), a lowresistance Hans Rudolph respiratory valve $(50 \mathrm{ml}$ dead space, outside diameter $34 \mathrm{~mm}$ ) and a noseclip, and then inhaled the conditioned air, assigned for that session, for $5 \mathrm{~min}$ whilst sitting. The child then performed the 7 min treadmill $\mathrm{Ch} 1$, at the predetermined speed and slope, whilst breathing the same conditioned air. At the end of exercise, the child came off the valve system and performed forced expiratory manoeuvres, at $0,3,5,7$, 10, 20 and 30 min post-exercise. The child was sitting comfortably during the $30 \mathrm{~min}$ rest interval, but spirometry was performed in the standing position. This was followed by treadmill exercise $\mathrm{Ch} 2$, using an identical exercise and recovery protocol, with the exception that inhaled air was always thermoneutral.

The same valve and tubing system was used throughout the study. To achieve warm-humid conditions the air was passed through an enclosed reservoir of heated water and then through a $2 \mathrm{~m}$ length of tubing $(34 \mathrm{~mm}$ internal diameter) wrapped with electric heating coil along its entire length. This helped maintain the required air temperature, which was monitored at the breathing valve (421 Yellow Springs thermistor, Yellow Springs, OH, USA). During thermoneutral conditions, inspired air bypassed the reservoir and the heating coil was turned off. 


\section{Calculations and data analysis}

The severity of EIA was calculated, using the $\%$ fall index for $\mathrm{FEV}_{1}$, as described by GoDFREY et al. [14]:

$$
\% \text { fall }=\frac{\text { pre-exercise }- \text { lowest postexercise value }}{\text { pre-exercise }} \times 100
$$

The pre-exercise value was the one that immediately preceded the respective challenge. The $\%$ fall following Ch1 placebo thermoneutral condition (session A table 3) was taken as the "standard" by which refractoriness was judged, as this was the only challenge in a thermoneutral environment and without indomethacin pretreatment, making it identical to all $\mathrm{Ch} 2 \mathrm{~s}$.

To assess the degree of refractoriness the "protection index" was calculated [15], as follows:

$$
\begin{aligned}
& \text { protection } \\
& \text { index }
\end{aligned}=\frac{\text { standard } \% \text { fall }-\% \text { fall in Ch2 }}{} \times 100
$$

A two-way repeated measures analysis of variance (ANOVA) was completed to identify differences in spirometry following the two pretreatment regimens and the two environmental conditions $(\mathrm{p}<0.05$ was taken as the level of significance).

\section{Results}

The resting pulmonary function values (table 1) ranged $63-119 \%$ of predicted (\% pred) [16], but were not significantly different between sessions. The mean resting $\mathrm{FEV}_{1}$ was $2.85 \pm 0.30 l$ ( $87 \%$ pred) for thermoneutral $\left(20-22^{\circ} \mathrm{C}, 25-35 \% \mathrm{RH}\right)$ and $2.82 \pm 0.26 l(85 \%$ pred) for warm-humid breathing conditions $\left(33-35^{\circ} \mathrm{C}, 90-95 \%\right.$ $\mathrm{RH})$, with mean values of $2.80 \pm 0.25 l(85 \%$ pred) prior to placebo trials and $2.85 \pm 0.32 l(87 \%$ pred $)$ prior to indomethacin tests. In addition, the $\mathrm{FEV}_{1}$ values were within $90 \%$ of control values prior to the $\mathrm{Ch} 2$ exercise challenge, and identical before $\mathrm{Ch} 2$ for placebo and indomethacin $2.79 \pm 0.28 l$ ( $84 \%$ pred). Table 3 presents the $\mathrm{FEV}_{1}$ values as $\%$ predicted for pre-exercise and as $\%$ fall for postexercise periods.

As shown in figure 1 , there was a significant $\%$ fall in $\mathrm{FEV}_{1}$ post $\mathrm{Ch} 1$ both for warm humid and thermoneutral conditions. However, the magnitude of the drop was significantly lower in the warm humid breathing condition $(34.4 \pm 4.1 \%$ versus $9.0 \pm 1.7 \%$ with placebo

\begin{tabular}{|c|c|c|c|c|c|c|c|c|}
\hline \multirow{3}{*}{$\begin{array}{l}\text { Subject } \\
\text { No }\end{array}$} & \multicolumn{4}{|c|}{ Placebo } & \multicolumn{4}{|c|}{ Indomethacin } \\
\hline & \multicolumn{2}{|c|}{ Neutral } & \multicolumn{2}{|c|}{ Warm-humid } & \multicolumn{2}{|c|}{ Neutral } & \multicolumn{2}{|c|}{ Warm-humid } \\
\hline & $\begin{array}{c}\text { Pre } \\
\% \text { pred }\end{array}$ & $\begin{array}{l}\text { Post } \\
\% \text { fall }\end{array}$ & $\begin{array}{c}\text { Pre } \\
\% \text { pred }\end{array}$ & $\begin{array}{l}\text { Post } \\
\% \text { fall }\end{array}$ & $\begin{array}{c}\text { Pre } \\
\% \text { pred }\end{array}$ & $\begin{array}{l}\text { Post } \\
\% \text { fall }\end{array}$ & $\begin{array}{c}\text { Pre } \\
\% \text { pred }\end{array}$ & $\begin{array}{l}\text { Post } \\
\% \text { fall }\end{array}$ \\
\hline \multicolumn{9}{|l|}{ Ch1 } \\
\hline 1 & 75 & 64 & 83 & 5.7 & 79 & 64 & 79 & 12 \\
\hline 2 & 70 & 38 & 66 & 4.2 & 73 & 30 & 75 & 15 \\
\hline 3 & 72 & 48 & 71 & 1.4 & 74 & 45 & 80 & 8.9 \\
\hline 4 & 119 & 24 & 123 & 9.6 & 122 & 12 & 115 & 0.5 \\
\hline 5 & 112 & 15 & 107 & 3.0 & 115 & 12 & 121 & 6.7 \\
\hline 6 & 89 & 33 & 82 & 23 & 85 & 18 & 89 & 34 \\
\hline 7 & 92 & 34 & 85 & 12 & 97 & 44 & 82 & 8.6 \\
\hline 8 & 63 & 44 & 68 & 13 & 66 & 37 & 65 & 43 \\
\hline 9 & 84 & 20 & 86 & 6.2 & 89 & 22 & 87 & 5.4 \\
\hline 10 & 85 & 23 & 83 & 5.3 & 88 & 20 & 84 & 4.8 \\
\hline 11 & 76 & 55 & 78 & 17 & 79 & 47 & 77 & 19 \\
\hline 12 & 83 & 32 & 87 & 12 & 81 & 33 & 84 & 12 \\
\hline 13 & 91 & 18 & 90 & 4.9 & 93 & 21 & 90 & 5.2 \\
\hline \multicolumn{9}{|l|}{ Ch2 } \\
\hline $1^{*}$ & - & - & 82 & 33 & - & - & 73 & 61 \\
\hline 2 & 71 & 19 & 78 & 12 & 69 & 37 & 77 & 29 \\
\hline 3 & 70 & 0.5 & 74 & 8.7 & 77 & 25 & 77 & 21 \\
\hline 4 & 122 & 4.5 & 123 & 2.2 & 122 & 15 & 119 & 21 \\
\hline 5 & 112 & 9.0 & 112 & 9.5 & 112 & 11 & 115 & 7.0 \\
\hline 6 & 83 & 12 & 83 & 2.0 & 78 & 20 & 108 & 37 \\
\hline 7 & 62 & 16 & 82 & 16 & 62 & 23 & 80 & 37 \\
\hline 8 & 60 & 24 & 68 & 21 & 61 & 55 & 60 & 51 \\
\hline 9 & 84 & 8.4 & 82 & 9.3 & 84 & 19 & 82 & 22 \\
\hline 10 & 82 & 13 & 84 & 13 & 86 & 17 & 85 & 20 \\
\hline 11 & 74 & 3.6 & 76 & 4.9 & 71 & 40 & 76 & 26 \\
\hline 12 & 86 & 11 & 90 & 12 & 87 & 25 & 86 & 25 \\
\hline 13 & 86 & 1.1 & 85 & 10 & 90 & 16 & 87 & 17 \\
\hline
\end{tabular}
and $31.2 \pm 4.3 \%$ versus $13.5 \pm 3.4 \%$ with indomethacin).

Table 3. - FEV 1 pre-exercise (\% pred) and postexercise values (\% fall) for exercise challenge 1 (Ch1) and challenge 2 (Ch2)

\footnotetext{
$\mathrm{FEV}_{1}$ : forced expiratory volume in one second. *: unable to complete 2nd exercise $\mathrm{Ch} 2$.
} 


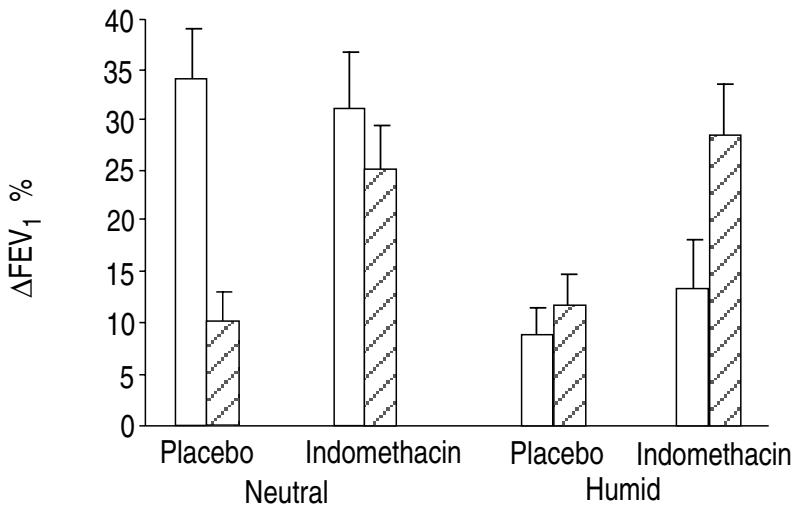

Fig. 1. - Percentage fall in $\mathrm{FEV}_{1}\left(\Delta \mathrm{FEV}_{1}\right)$, postexercise compared to pre-exercise values. Data are presented as mean \pm SEM. Placebo and indomethacin pretreatments are compared under thermoneutral and warm-humid breathing conditions (see text). $\square$ : Challenge 1;

$\square$ : Challenge 2. $\mathrm{FEV}_{1}$ : forced expiratory volume in one second.

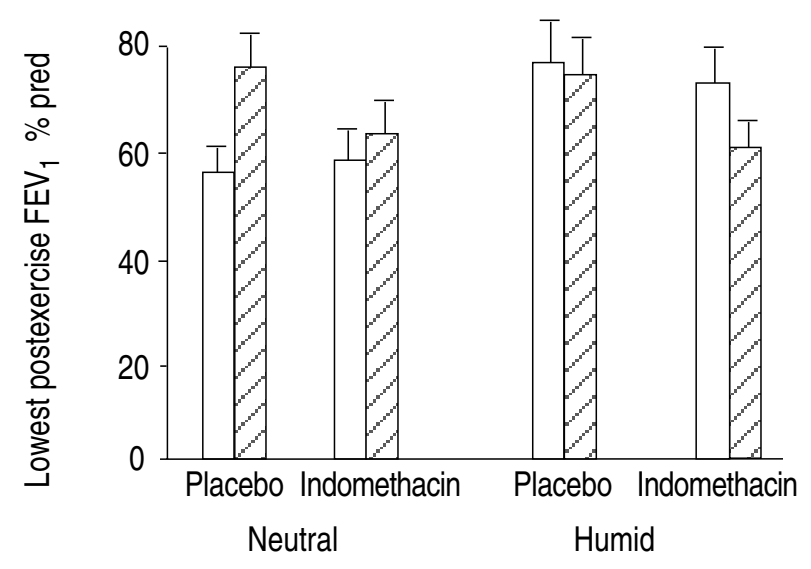

Fig. 2. - Lowest postexercise $\mathrm{FEV}_{1}$ expressed as \% predicted value. Data are presented as mean \pm SEM. Placebo and indomethacin pretreatments are compared under thermoneutral and warm-humid breathing conditions (see text). $\square$ : Challenge 1; $\square$ : Challenge 2. FEV : forced expiratory volume in one second.

There was no significant effect of the indomethacin treatment on any of the exercise parameters or $\mathrm{FEV}_{1}$ changes post Ch1. The values for $\%$ fall in $\mathrm{FEV}_{1}$ post Ch2 (placebo session) were not significantly different between thermoneutral $(10.2 \pm 2.0 \%)$ and warm-humid $(11.8 \pm 2.3 \%)$ conditions (fig. 1). They were, however, significantly lower than indomethacin trials, which produced a $\%$ fall in $\mathrm{FEV}_{1}$ post $\mathrm{Ch} 2$ of $25.2 \pm 3.7 \%$ for thermoneutral and $28.7 \pm 4.0 \%$ for warm-humid.

When the $\%$ fall in $\mathrm{FEV}_{1}$ changes are expressed as the protection index, both breathing conditions produced similar degrees of protection, placebo thermoneutral 70 $\pm 7.8 \%$ protection and placebo warm-humid $67 \pm 8.1 \%$. However, indomethacin trials resulted in significantly less protection, thermoneutral $26 \pm 6.8 \%$ and warmhumid $16 \pm 5.7 \%$. Figure 2 presents the lowest values for $\mathrm{FEV}_{1}$ after exercise as \% of predicted values. Significant reduction in the EIA response post $\mathrm{CH} 1$ warmhumid trials is evident as well as significantly reduced refractoriness during the indomethacin trials.

\section{Discussion}

The results from the present study confirm that inhalation of warm-humid air attenuates the bronchoconstrictor response to challenge with exercise $[5,10,11$, 13]. Because subjects showed refractoriness both after exercise challenges that produced bronchoconstriction (thermoneutral trials) and after reduced or nonbronchoconstricting bouts (warm-humid trials), airway constriction was not an essential trigger of refractoriness in these subjects.

This finding is supported by previous work from our laboratory [13], and findings of BEN-Dov et al. [12]. However, others have found no refractoriness after non-asthma-producing exercise [17, 18], a pattern similar to that found after hyperventilation-induced asthma [19]. It is attractive to speculate that the discordance between hyperventilation and exercise-induced refractoriness is due to different mechanisms operating during the two challenges. For example, there may be a refractory response resulting from respiratory heat loss which is common to both exercise and hyperventilation, and in addition a refractory period specifically resulting from exercise.

When our subjects were pretreated with indomethacin the percentage protection afforded them was significantly reduced (fig. 2), thus implicating the prostaglandin system in the response. It has been reported that prostaglandins are elevated in the airways of even mild asthmatics [20], and that indomethacin can block refractoriness after asthma-producing exercise [9]. Our data demonstrate that prostaglandins also play a role in the refractory period after non-asthma-producing exercise. Since the non-asthma-producing exercise was performed whilst breathing warm-humid air and reduced respiratory heat loss, the blockage of the refractory effect by indomethacin suggests that it is exercise per se that triggers the release of inhibitory prostaglandin. It should be noted that indomethacin did not completely eliminate the refractory period, as a mean protection index of $21 \pm 6.2 \%$ was maintained after these trials. This indicates that some degree of protection is not prostaglandin-mediated or that not enough indomethacin was given. In addition, since the degree of bronchoconstriction post $\mathrm{Ch} 1$ was not affected by indomethacin treatment (fig. 1), then prostaglandins appear not to play a major role in the EIA caused by the initial challenge.

Considering the suggestion of GILBERT et al. [4], indomethacin could alter the responsivity of the bronchial microcirculation affecting the degree of airway cooling. The degree of protection remaining postindomethacin could indicate protection provided from a system triggered by respiratory heat loss, as $27 \%$ protection remained after thermoneutral trials and only $17 \%$ after warm-humid trials. This may be further supported by two of the subjects, Nos 6 and 8, whose EIA was not blocked by the warm-humid conditions during Ch1 indomethacin trials while they had a mean negative protection index of $5 \%$ following $\mathrm{Ch} 2$ indomethacin trials. This may explain why indomethacin does 
not appear to be effective in blocking the refractory period for hyperventilation-induced asthma [21]. Similar results could occur if the synthesis of prostaglandin was not effectively inhibited, however this is unlikely at the doses chosen [22].

The significance of the effect of indomethacin on refractoriness may best be illustrated by one subject, (subject 1) who was unable to complete the second exercise bout after either of the thermoneutral Ch1s, but, however, responded positively to the warm-humid breathing trials reducing her $\mathrm{FEV}_{1}$ fall from 64 to $6 \%$ after Ch1. This allowed her to complete the second exercise bout resulting in essentially $50 \%$ protection for the placebo trial and $0 \%$ protection for the indomethacin trial.

In summary, the data support the following general conclusions: warm-humid air breathing can effectively reduce EIA; a refractory period can be produced following both exercise resulting in EIA and exercise where the EIA is blocked by breathing warm-humid air; the degree of protection afforded is significantly reduced with indomethacin pretreatment. These conclusions suggest that inhibitory prostaglandins, most probably $\mathrm{PGE}_{2}$, are responsible for the exercise refractory period in the group of teenagers tested, and that the primary trigger for their release is not airway drying and cooling but some general exercise factor.

\section{References}

1. Edmunds AT, Tooley M, Godfrey S. The refractory period after exercise-induced asthma: its duration and relation to the severity of exercise. Am Rev Respir Dis 1978; 117: 247-254.

2. Lee TH, Nagy L, Nagakura T. Identification and partial characterization of an exercise-induced neutrophil chemotactic factor in bronchial asthma. J Clin Invest 1982; 69: 889-894.

3. Anderson SD, Bye PTP, Schoeffel RE. Arterial plasma histamine levels at rest, during and after exercise in patients with asthma: effects of terbutaline aerosol. Thorax 1981; 36: 259-264.

4. Gilbert IA, Fouke JM, McFadden ER. The effect of repetitive exercise on airway temperatures. Am Rev Respir Dis 1990; 142: 826-831.

5. Anderson SD, Schoeffel RE. Respiratory heat and water loss during exercise in patients with asthma: effect of repeated exercise challenge. Eur J Respir Dis 1982; 63: 472-478.

6. Hamielec CM, Manning PJ, O'Byrne PM. Exercise refractoriness after histamine inhalation in asthmatic subjects. Am Rev Respir Dis 1988; 138: 794-798.
7. Jackson PJ, Manning PJ, O'Byrne PM. A new role for histamine $\mathrm{H}_{2}$-receptors in asthmatic airways. Am Rev Respir Dis 1988; 138: 784-788.

8. Manning PJ, Jones GL, O'Byrne PM. Tachyphylaxis to inhaled histamine in asthmatic subjects. J Appl Physiol 1987; 63: 1572-1577.

9. O'Bryne PM, Jones GL. The effects of indomethacin on exercise-induced bronchoconstriction and refractoriness after exercise. Am Rev Respir Dis 1986; 134: 69-72.

10. Bar-Or O, Neuman I, Dotan R. Effects of dry and humid climates on exercise-induced asthma in children and adolescents. J Allergy Clin Immunol 1977; 60: 163168.

11. Hahn A, Anderson SA, Morton A, Black J, Fitch K. A reinterpretation of the effect of temperature and water content of the inspired air in exercise-induced asthma. Am Rev Respir Dis 1984; 130: 575-579.

12. Ben-Dov I, Bar-Yishay E, Godfrey S. Refractory period after exercise-induced asthma unexplained by respiratory heat loss. Am Rev Respir Dis 1982; 125: 530534.

13. Wilson BA, Bar-Or O, Seed LG. Effects of humid air breathing during arm or treadmill exercise on exerciseinduced bronchoconstriction and refractoriness. Am Rev Respir Dis 1990; 142: 349-352.

14. Godfrey S, Silverman M, Anderson SA. Problems of interpreting exercise-induced asthma. J Allergy Clin Immunol 1973; 52: 199-209.

15. Schoeffel RE, Anderson SD, Gillam I, Lindsay DA. Multiple exercise and histamine challenges in asthmatic patients. Thorax 1980; 35: 164-170.

16. Godfrey S, Kamburoff PL, Nairn JR. Spirometry, lung volumes and airway resistance in normal children aged 5 to 18 years. Br J Dis Chest 1970; 64: 15-24.

17. Anderson SA, Daviskas E, Schoeffel RE, Unger SR. Prevention of exercise-induced asthma with hot humid air. Lancet 1979; 2: 629-634.

18. Hahn AG, Nogrady SG, Burton GR, Morton AR. Absence of refractoriness in asthmatic subjects after exercise with warm, humid inspirate. Thorax 1985; 40: 418-426.

19. Bar-Yishay E, Ben-Dov I, Godfrey S. Refractory period after hyperventilation-induced asthma. Am Rev Respir Dis 1983; 127: 572-574.

20. Lui MC, Bleecker ER, Lichtenstein LM, et al. Evidence for elevated levels of histamine, prostaglandin $\mathrm{D}_{2}$ and other bronchoconstricting prostaglandins in the airways of subjects with mild asthma. Am Rev Respir Dis 1990; 142: 126-132.

21. Margolskee DJ, Bigby BG, Boushey HA. Indomethacin blocks airway tolerance to repetitive exercise but not to eucapnic hyperpnea in asthmatic subjects. Am Rev Respir Dis 1988; 137: 842-846.

22. Ferreira SH, Moncada S, Vane JR. Indomethacin and aspirin abolish prostaglandin release from spleen. Nature 1971; 231: 237-239. 